\title{
Evaluation of the antibacterial potential of polyphenols against periodontal pathogens
}

\author{
M. Shahzad ${ }^{1}$, G. Ramage ${ }^{2}$, C. A. Edwards ${ }^{1}$ and E. Combet ${ }^{1}$ \\ ${ }^{1}$ Human Nutrition, School of Medicine, College of MVLS, University of Glasgow, Glasgow, G3 8SJ, UK and ${ }^{2}$ Glasgow \\ Dental School, Institute of Infection and Immunity, College of MVLS, University of Glasgow, 378 Sauchiehall Street, \\ Glasgow, G2 3JZ, UK
}

Periodontal disease is a common, chronic infectious disease triggered by the bacterial biofilm of dental plaque resulting in inflammatory loss of the tooth supporting tissues ${ }^{(1)}$. Globally, it affects $5-70 \%$ of the older (above 65 years) population ${ }^{(2)}$ and can impact on their diet and nutrition leading to weight loss, as well as increase the risk for chronic diseases like diabetes mellitus and cardiovascular disease ${ }^{(3)}$. In recent years, specific dietary compounds, especially the polyphenolics have attracted scientific attention due to their health promoting potential. As a regular constituent of the human diet, polyphenols offer a promising alternative in the prevention of microbiota-related oral diseases via their relative safety (at physiological level) and antioxidant, antibacterial and, anti inflammatory potentials ${ }^{(4)}$. For successful manipulation of polyphenols in functional foods and healthcare products, it is necessary to study their antibacterial effects. The aim of the present study was to evaluate the antibacterial activity of a range of polyphenols against selected periodontal pathogens, with emphasis on structure-function relationship.

Polyphenolic compounds ( $n=46$, from 8 subgroups) were screened for their antimicrobial activity against four periodontal pathogens: two aerobic, Streptococcus mitis (Sm) and Actinobacillus actinomycetocommitans (Aa) and two anaerobic, Fusobacterium nucleatum (Fn) and Porphyromonas gingivalis $(\mathrm{Pg})$. The antimicrobial potential of each compound was evaluated in terms of minimum inhibitory concentration (MIC) and minimum bactericidal concentration (MBC) using plate dilution assay following standard clinical and laboratory (CLSI) guidelines. Chlorhexidine $(0.2 \%)$, well known for its antimicrobial properties, was used as a reference.

All polyphenols tested displayed antimicrobial properties against one or more test strains except kaempferol-3-glucoronoid, epicatechin, malvin (highest concentration tested: $250 \mu \mathrm{g} / \mathrm{ml}$ ), theaflavin, procyanidin B2 (highest concentration tested: $125 \mu \mathrm{g} / \mathrm{ml}$ ). Curcumin was found to be the most potent with MIC range of 7.81-62.5 $\mu \mathrm{g} / \mathrm{ml}$ against all test strains (highest activity against $p g$ and $F n$ ), followed by pyrogallol (MIC 2.4-312.5 $\mu \mathrm{g} / \mathrm{ml}$ ) and pyrocatechol (MIC 4.88-312.5 $\mu \mathrm{g} / \mathrm{ml}$ ) which were highly effective against $S m$ and $A a$. Apigenin and diadzein were only effective against anaerobic bacteria (MIC $15.6-125 \mu \mathrm{g} / \mathrm{ml}$ and $15.6-500 \mu \mathrm{g} / \mathrm{ml}$, respectively). MBC for most of the polyphenols was either the same or twice the MIC. More polyphenolic compounds were effective in inhibiting the growth of the Gram - ve $A a$ (34/46 tested) than the growth of the Gram + ve Sm (23/46 tested); the concentration needed was 3 times lower, with a mean MIC of $341.0 \mu \mathrm{g} / \mathrm{ml}$ (SD 94) vs. a mean MIC of $1061.8 \mu \mathrm{g} / \mathrm{ml}$ (SD 921), $p<0.001$. Aglycones were more potent inhibitors of growth compared to their corresponding glycosides in all strains: mean MIC 122.1 $\mu \mathrm{g} / \mathrm{ml}$ (SD 117) $v s .519 .5 \mu \mathrm{g} / \mathrm{ml}$ (sD460), respectively, $p<0.001$. With the presence of an extra OH group, the MIC against $A a$ decreased (3-hydroxybenzoic acid vs. 3,4-dihydroxybenzoic acid $v s .3,4,5$-trihydroxybenzoic acid; $625 \mu \mathrm{g} / \mathrm{ml} v s .312 .5 \mu \mathrm{g} / \mathrm{ml} v s .9 .6 \mu \mathrm{g} / \mathrm{ml}$ ). The MIC against $A a$ was also affected by location of the OH group (1,2-dihydroxybenzene vs. 1,3-dihydroxybenzene; MIC $4.88 \mu \mathrm{g} / \mathrm{ml} v s .1250 \mu \mathrm{g} / \mathrm{ml})$.

This study shows that polyphenols are endowed with antibacterial properties against periodontopathic bacteria, indicating that they have the potential to prevent periodontal diseases. These properties are affected by bacterial strain and properties as well as the structure of the polyphenolic molecule.

1. Page RC, Offenbacher S, Schroeder HE, et al. (1997) Periodontol 14, 216-48.

2. WHO Oral Health Country/Area Profile. Available from: http://www.whocollab.od.mah.se/index.html

3. Petersen PE, Yamamoto T (2005) Community Dent Oral Epidemiol 33(2), 81-2.

4. Palombo EA. (2011) Evid-Based Compl Alt 11, 1-15. 